\title{
EL INSTITUTO DE CONSERVACIÓN Y RESTAURACION DE BIENES CULTURALES Y LA FORMACION DEL CONSERVADOR-RESTAURADOR
}

\author{
$M^{a}$ Dolores Ruiz \\ de Lacanal Ruiz-Mateos \\ Facultad de Bellas Artes. \\ Universidad de Sevilla.
}

Los antecedentes

El Instituto nace, y así queda expresado en la introducción del Decreto de creación de 16 de noviembre de 1961, con el fin de "dotar al país de un Organismo que con las garantías científicas y técnicas necesarias pueda atender a la tarea de restauración y conservación de las obras y objetos de que se trata, sin que su actuación perturbe, como ahora sucede, el normal funcionamiento de los Talleres de Restauración existentes en los Museos Nacionales y cuya actividad pueda desplegarse de tal modo que quede asegurada la rapidez de las restauraciones necesarias, y en todo caso sin demoras ni dilaciones, que puedan conducir a pérdidas irreparables"'.

Nace de la necesidad de dotar al país de un Servicio de Conservación y Restauración independientemente de los talleres de restauración de los Museos Nacionales. Retoma pues, como punto de partida, la Junta de Conservación y Restauración de Obras de Arte Antiguo, nacida en 1924 con el fin de conservar y restaurar las obras de arte, asociada en un primer momento a los propios talleres de restauración del Museo Nacional del Prado.

Digamos por tanto que sus antecedentes más inmediatos remiten a los principios del siglo $X X$, pudiéndose detectar sus orígenes a partir de los siguientes documentos: el Reglamento para el régimen de los Museos Arqueológicos del Estado $(1901)^{2}$, el Reglamento para la organización y régimen del Museo Nacional del Prado, en cuyas páginas queda establecida la organización de los Talleres de Restauración (1920)3 , el documento que contiene las reglas acerca de la Organización del Servicio de Conservación y Restauración de Pinturas y obras de arte existentes en provincias, templos, colecciones públicas o fundaciones $(1924)^{4}$ y el Decreto de la constitución de la Junta de Conservación y Restauración de pinturas y obras de Arte Antiguo (1924) . $^{5}$

Aquel Servicio de Conservación y Restauración a su vez era una realidad frente a los deseos expresados por Claudio Boutelou en 1880, sobre la necesidad de crear con fondos públicos un servicio capaz de atender tanto a Museos como a obras de otras entidades o de provincia 6 . Pudiéndose decir en resumen que el Instituto Central de Restaura- ción y Conservación de Obras y Objetos de Arte, Arqueología y Etnología es fruto del "constante interés de los Poderes Públicos por la conservación y restauración de las obras y objetos" que son dignos de valorar y conservar.

Heredero de la Ley del 13 de mayo de 1933, Ley de defensa, conservación y acrecentamiento del patrimonio histórico-artístico nacional, queda orientado hacia la Conservación y Restauración de las obras y objetos que integran el Patrimonio Artístico y Arqueológico, a lo que viene a sumarse los objetos de etnología, citados en la propia denominación, estando a las puertas del concepto de Bienes Culturales. Una transformación que se produciría posteriormente a la declaración de la Ley del Patrimonio Histórico Español de 1985, concretamente por el Real Decreto de 24 de abril de 1985 en el que pasa a llamarse Instituto de Conservación y Restauración de Bienes Culturales.

El Instituto Central de Conservación y Restauración y el panorama europeo. Misión UNESCO en España. Paul Coremans

A esta perspectiva histórica debe sumarse otra más amplia que intente comprender el panorama europeo. El mapa de los organismos nacidos en el siglo es suficientemente ilustrativo: en 1933 surge el Instituto Courtauld de Londres, en 1939 nace el Instituto Central del Restauro en Roma, en 1945 se forma la Facultad de Conservación en la Academia de Bellas Artes de Varsovia, en 1960 el establecimiento del Instituto de Bellas Artes de la Universidad de Nueva York?.

Esta situación es el resultado del desarrollo de la conciencia internacional de la necesidad de crear una estructura adecuada para la Conservación y Protección del Patrimonio Cultural. Fruto de esta preocupación fueron entre otras la Conferencia Internacional para la Conservación del Patrimonio Artístico Arqueológico, celebrada en Atenas en 1931, origen de la Carta del Restauro o la Conferencia Internacional para el Examen y preservación de Obras de Arte convocada por el Oficio Internacional de Museos de la Sociedad de Naciones celebrada en Roma en $1930^{8}$.

Con el asesoramiento de la UNESCO se desarro- 
Ilan en los países miembros Centros de Conservación y Restauración: "Desde su fundación, la UNES$\mathrm{CO}$ ha organizado numerosas misiones de consultores a muchos países con objeto de asesorar a los países miembros o a sus instituciones sobre la preservación de los objetos de museo, de los monumentos y de los lugares de interés arqueológico"g.

Un portavoz y mensajero de la UNESCO, Paul Coremans $^{10}$, llegaría a España en 1959, con motivo del simposio sobre restauración monumental celebrado en Madrid"' trayendo la misión UNESCO en España: El Instituto Central de la Conservación y Restauración ${ }^{12}$.

Su organización respondía al modelo establecido por la UNESCO, recogidos y expresados por Coremans en "La organización de un servicio nacional de preservación de los Bienes Culturales". En el informe plantea un modelo susceptible de ser adaptado a las características de la estructura social, política o administrativa particulares de cada país, a los medios disponibles, su riqueza, su distribución geográfica y a otras consideraciones", pero con los objetivos centrados en la investigación, educación y exposición y conservación de los Bienes Culturales. Las funciones de la sección de conservación incluyen laboratorios científicos y técnicos, talleres de Restauración y centros de formación especializada, además de los centros de formación superior ya existentes. Unos objetivos a conseguir en fases sucesivas.

El reconocimiento a la labor de Paul Coremans quedaba recogido en las palabras del Director General de Bellas Artes, Gratiano Nieto Gallo, expresadas en 1965, a raíz de su fallecimiento:"Respondemos también con ello a la atención que la UNESCO viene prestando al Instituto, del que fue valioso mentor el Dr. Coremans, cuya pérdida nunca lamentaremos bastante y cuyo recuerdo no podemos dejar de asociar a cuantas tareas colectivas se planteen, encaminadas a la Conservación del Patrimonio Mundial"'/4.

\section{El Instituto y el Sistema de protección del Patrimo- nio Histórico Español}

Las reformas del Sistema para la Protección del Patrimonio Histórico Español deben ser comprendidas ahora con respecto al propio Instituto de Conserva- ción y Restauración, un organismo nacido para centralizar las tareas de Conservación y Restauración de Bienes Muebles pertenecientes al Patrimonio Histórico Español, que funciona paralelamente en su primera fase con otras instituciones: el Centro Nacional de Restauración de Libros y Documentos, el Instituto de Conservación y Restauración de Monumentos y conjuntos Histórico-artísticos, la Junta de Calificación,Valoración y Exportación de obras de importancia histórica $\mathrm{O}$ artística, el Centro Internacional de Información Artística, Arqueológica y Etnológica, entre otros ${ }^{15}$.

En 197I el ICROA, Instituto de Conservación y Restauración de Obras de Arte, centraliza las tareas de Conservación y Restauración de los bienes muebles pertenecientes al Patrimonio Histórico Español. En su segunda fase, creado el Ministerio de Cultura, establecidas las competencias de las autonomías y delimitada las competencias de la Administración del Estado, se transforma en el Instituto de Conservación y Restauración de Bienes Culturales por Real Decreto del 24 de abril de 1985, constituyéndose como "un órgano moderno de la administración del Estado especializado en la protección, conservación y restauración de los Bienes Culturales y agrupando los organismos hasta ahora dispersos especializados en la Conservación del Patrimonio".

El Instituto de Conservación y Restauración de Bienes Culturales quedaba integrado por el ICROA, el Instituto de Conservación y Restauración de Obras de Arte, el CECOMI, Centro de Conservación y Microfilmación Documental y Bibliográfica, la Subdirecciones Generales de Restauración de Monumentos y Arqueología' ${ }^{6}$. Se llegaba al Servicio Nacional para la preservación de Bienes Culturales potenciado por la UNESCO.

\section{El Instituto de Conservación y Restauración de Bienes Culturales y la formación del Conservador- Restaurador}

En el decreto de creación el Instituto queda organizado como un gran taller de Restauración que cuenta con "talleres de restauración de pintura, escultura, mosaico, elementos arquitectónicos, mobiliario, tapices, vidrieras, metales, cerámica, objetos arqueológicos y etnológicos varios así como otros que las necesidades aconsejen poner en funcionamiento" (art. 3d). Cuenta, acorde con el nue-
Las estructuras politicas, administrativas y

las coordenadas docentes y culturales de España a finales del siglo XX se han visto profundamente alteradas. En este proceso de cambio el perfil del conservador-restaurador ba tenido que enfrentarse a nuevos problemas de mayor complejidad, a problemas de nuestro tiempo, un tiempo europeo, aunque mejor, un tiempo internacional 


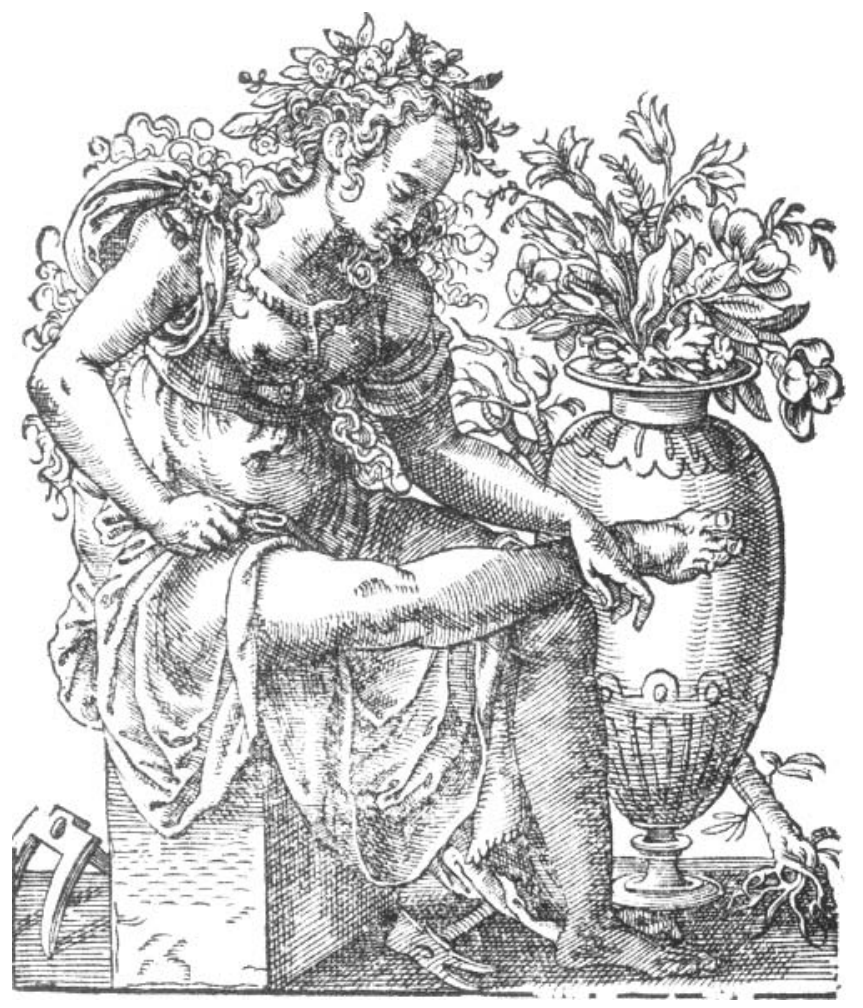

vo planteamiento de la Conservación y Restauración, de laboratorios dotados científica y técnicamente, es decir, con laboratorio de Física, Química, laboratorio de radiografía y fotográfico (art. 3 b y c). Es también un centro de reunión, estudio y difusión de documentación sobre los problemas científicos y técnicos (art. 2h), contando con archivos para la documentación de obras restauradas y biblioteca especializada en los problemas de conservación y restauración (art. 3e y f) ${ }^{17}$.

Es además un centro de formación, y no sólo por nacer la Escuela de Procedimientos y Arte de la Restauración y Museología, contemplada inicialmente entre sus servicios, sino por ser centro que contribuye a la formación de investigadores y técnicos, permitiendo el contacto con especialistas de otros países y la salida al extranjero del personal español con fines de especialización.

La creación del Instituto en España transforma sustancialmente el panorama de la formación del Conservador-Restaurador español.

Se puede distinguir entre la formación del Conservador-Restaurador desde la creación del Instituto y la formación del Conservador-Restaurador cuyas enseñanzas son impartidas por la Escuela de Conservación y Restauración. Señalaremos algunos de los principales aspectos de la formación del Conservador-Restaurador en relación a la creación del Instituto:

La formación de los Conservadores-Restauradores mejora en cuanto que aumenta el estudio, la difu- sión, documentación, publicación, investigación de los problemas técnicos de la Conservación y Restauración y posibilita un cauce de formación en base a las relaciones internacionales y conciertos e intercambios de conocimientos, experiencias y métodos $^{18}$

Aparece en el panorama español la primera biblioteca especializada en materia de Conservación y Restauración. La escasez bibliográfica que existía en España, incide en la formación de los profesionales, pudiéndose afirmar que abre el principio de otra etapa ${ }^{19}$. Dicha formación se beneficia de sus publicaciones, traducciones e investigaciones. Desde aquel primer tratado sobre "El Arte de la Restauración" de Vicente Poleró y Toledo y los informes de las Restauraciones acometidas por la Academia en el siglo XIX poco se publicaba en España. Los conocimientos se ven ahora enriquecidos con las publicaciones de los informes del Instituto, recogidos en sus archivos, material que es imprescindible y fundamental para el estudio de la Conservación y Restauración y Conservación del siglo XX español. Anotemos, por ejemplo, la reimpresión de los tratados de Vicente Poleró y Toledo y de Mariano de la Roca y Delgado, reimpresos y dados a conocer a través de sus publicaciones.

Cambian sustancialmente los contenidos de formación, con la introducción de medios y técnicas más recientes; no sólo conocimiento teórico sino formación práctica e investigación. La asistencia de nuestros especialistas a conferencias y encuentros europeos conlleva la introducción en España de contenidos hasta entonces desconocidos en nuestro país, sobre Conservación y Restauración de textiles, de papel, grabados y dibujos, climatología de Museos, Ciencias Químicas Aplicada a la Conservación y Restauración, entre otras materias ${ }^{20}$.

Se transforma el concepto de espacio docente para la Restauración y Conservación, al nacer un servicio con laboratorios de física, química y radiografía, laboratorio fotográfico, talleres de Restauración, archivos o biblioteca. Espacio, infraestructura, medios, se añaden a unos contenidos de formación: un taller, que no es un espacio "para" o espacio físico sino espacio cualificado y dotado "con". Y finalmente una formación y preparación de técnicos, conectada con la finalidad y la demanda: "la formación y preparación de técnicos que puedan servir adecuadamente a las finalidades expresadas, así como a las que se refieren a la instalación y conservación de las colecciones en los Museos y en otros lugares donde deban exhibirse".

De la Escuela de Procedimientos, Arte de la Restauración y Museología a la Escuela Superior de Conservación y Restauración de Bienes Culturales

La Escuela se organiza en 1961 bajo la denominación de Escuela de Procedimientos y Arte de la Restauración y Museología. En el decreto de creación el Ministerio de Educación Nacional expresa lo 
siguiente:"un centro de formación de técnicos a los que hayan de encomendarse en el futuro las tareas de conservación y restauración de que se trata hace aconsejable el que en íntima relación con el Instituto Central de Restauración exista una Escuela orientada al expresado fin".

Quedan adscritos al Instituto los profesores y el personal técnico provenientes de las Cátedras y a los Talleres de Restauración de las Escuelas de Bellas Artes y, con carácter temporal, personal técnico de los Talleres de los Museos Nacionales²!

La Reglamentación de la Escuela se establece en 1969, tomando el nombre de Escuela de Artes Aplicadas a la Restauración 22 quedando regulada como una Escuela de Artes Aplicadas y Oficios Artísticos aunque rompe las barreras entre artes mayores y menores, uniendo la formación para la Conservación y Restauración "de obras y objetos de todo orden que integran el Patrimonio Artístico y Arqueológico de la nación". Sus estudios, distribuidos en tres cursos teórico-prácticos, finalizan con el Título o Diploma de Restaurador, equiparable al expedido por las Escuelas Superiores de Bellas Artes.

En 1971, la Escuela pasa a designarse Escuela de Conservación y Restauración de Obras de Arte y queda organizada independiente al Instituto.

En el Decreto se contempla la división de la Dirección compuesta por la Comisión Directiva, el Director Gerente, el DirectorTécnico y el Director de la Escuela, que queda encargado de la Dirección de la Escuela, cumplimiento de los horarios, disciplina de alumnado y distribución de créditos ${ }^{23}$.

José $M^{a}$ Cabrera recoge con estas palabras el cambio: "Se creó por Decreto 2.415/1961 de 16 de noviembre. Se reorganizó diez años más tarde, por Decreto 2.093/197| con el principal propósito de repartir las tres direcciones (Administrativa, Técnica y de la Escuela) la función unitaria del Director fundador, consiguiéndose la dimisión del mismo y la paralización del Instituto durante casi una década"24.

Gloria González-Úbeda Rico indica los motivos del cambio: "Inicialmente montado sobre la doble vertiente de la restauración por un lado y la investigación y la docencia por otro, este último aspecto, no obstante, se desliga del Instituto para pasar a la órbita competencial del Ministerio de Educación al ser integrado aquél en el Ministerio de Cultura"25.

En 1987, por Orden de 21 de enero, se aprueba el Plan de estudios de la Escuela de Artes Aplicadas a la Restauración y pasa a llamarse Escuela de Conservación y Restauración de Bienes Culturales ${ }^{26}$.

Para el ingreso a las enseñanzas se establece un examen constituido por una prueba escrita sobre un tema general relacionado con los Bienes Culturales, un ejercicio de Dibujo y Color y un test de aptitud plástica. Al fin de los estudios los alumnos reciben el título de Restaurador y Conservador de Bienes Culturales ${ }^{27}$.

\section{El punto de confluencia: la aprobación de las ense- ñanzas de Conservación y Restauración de Bienes Culturales y la Escuela Superior de Conservación y Restauración de los Bienes Culturales de Madrid}

En 1991, España ha logrado cubrir la fase de transformación de las estructuras políticas y administrativas heredadas del pasado. Unas estructuras, que han evolucionado conviviendo en su disparidad, unas viejas otras nuevas, en un proceso de reciclaje, cuyos numerosísimos pasos, sólo el legislador podría llegar realmente a precisar.

Las estructuras políticas, administrativas y las coordenadas docentes y culturales de España a finales del siglo $X X$ han cambiado. $Y$ en este proceso de cambio el perfil del Conservador-Restaurador ha tenido que enfrentarse a problemas de gran complejidad.

El Conservador-Restaurador en España a finales del siglo $\mathrm{XX}$ es un hijo de nuestro tiempo, un tiempo europeo, aunque mejor un tiempo internacional. En el plano nacional, la creación del Instituto de Conservación y Restauración, era el organismo creado por los Poderes Públicos para sustituir finalmente a la Antigua Junta de Conservación de Obras de Arte. Administrativamente, los restauradores antiguos de la Junta de Conservación de Obras de Arte quedaban transformados en Restauradores del Instituto;

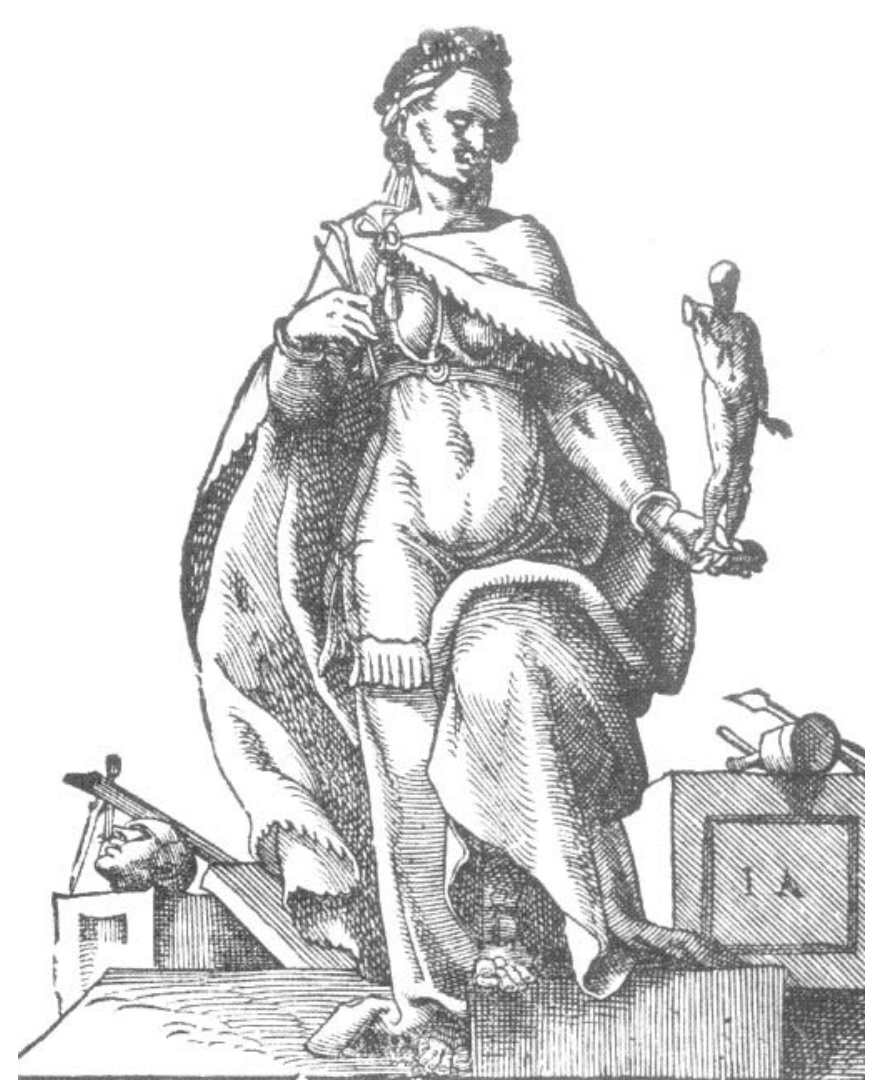


mientras, las estructuras administrativas capaces de lograr los objetivos establecidos en la nueva Ley del Patrimonio Histórico-Artístico y la delimitación de competencias de las Autonomías transformaban la realidad del profesional y su ámbito de acción a través de los Institutos de las Autonomías. El Conservador-Restaurador de Bienes Culturales, se ha configurado bajo las reformas administrativas de la función pública y se ha cubierto el proceso de reciclaje de titulaciones, de perfiles y de cualificaciones tendiendo un puente de paso para que los profesionales de cualquier área o cualquier institución puedan transformarse no sólo administrativamente sino también académica y profesionalmente. A este proceso aún en curso hay que añadir la Reforma de los nuevos Planes de Estudio sobre la base de los nuevos títulos universitarios de carácter oficial y con validez en todo el territorio nacional28.

En este proceso las Escuelas de Bellas Artes entran a formar parte de las Reformas de la Enseñanzas Universitarias comenzando un proceso de elaboración y estudio de los nuevos planes de estudio ${ }^{29}$.

En todos los campos de la Administración, estatal y autonómico, se estudian los perfiles profesionales, los curriculum y cualificaciones, los grados y jerarquías y sus enseñanzas ${ }^{30}$.

El Ministerio de Educación y Ciencia ha aprobado el conjunto de enseñanzas mínimas: La Ley Orgánica 1/1990, de 3 de octubre, de Ordenación General del Sistema Educativo define los Estudios correspondientes a la Especialidad de Conservación y Restauración de Bienes Culturales como estudios superiores y en 1991, por Orden de 28 de octubre, se aprueba el currículum y se regulan las enseñanzas, que tendrán por finalidad la formación de los profesionales, a los que ha de encomendarse las tareas de Conservación y Restauración de obras y objetos que integran el Patrimonio Histórico.

El plan de estudios de Conservación y Restauración de Bienes Culturales comprenderá tres cursos, de los cuales el primero será común y los dos siguientes de especialidad. Las Especialidades son:

a) Conservación y Restauración de Arqueología.

b) Conservación y Restauración de Pintura y Escultura.

c) Conservación y Restauración de documento gráfico.

d) Conservación y Restauración de textiles.

Se expresan los siguientes objetivos:

a) Conocimiento y valoración del significado y función de los Bienes Culturales, relacionándolos con su contexto histórico y artístico.

b) Conocimiento de los materiales constitutivos de los Bienes Culturales y de los agentes de deterioro más comunes.

c) Apreciación y valoración crítica de la teoría y los criterios de Restauración. d) Adquisición y destreza necesarias para utilizar con precisión los procedimientos y técnicas para llevar a cabo los trabajos de Conservación y Restauración de Bienes Culturales.

e) Adquisición de una base de conocimientos legales, técnicos y administrativos relacionados con la función de peritaje, custodia y difusión del Patrimonio Histórico.

f) Conocimiento general y correcta integración de las diversas disciplinas que, desde otros ámbitos, inciden en los Bienes Culturales, desarrollando la capacidad de trabajar con aprovechamiento en equipos de carácter interdisciplinar.

g) Capacidad para utilizar, en la intervención sobre los Bienes Culturales, de manera adecuada e integrada los diversos criterios, conocimientos y habilidades adquiridos durante el proceso de aprendizaje"3!.

Los alumnos que aprueben las asignaturas obtendrán el título de Conservación y Restauración de Bienes Culturales, que será equivalente a todos los efectos al Diplomado Universitario. Los que hayan obtenido el título podrán incorporarse al segundo ciclo de enseñanza universitaria, de acuerdo con los artículos $5^{\circ}$ y $8^{\circ}$ del Real Decreto I.497/1987, de 27 de noviembre en el que se establecen los planes de estudio de los títulos universitarios de carácter oficial y con validez en todo el territorio nacional.

La Escuela de Conservación y Restauración de Bienes Culturales de Madrid pasará a denominarse Escuela Superior de Conservación y Restauración de Bienes Culturales.

Si el 18 de septiembre de 199| se publicaban las enseñanzas mínimas de Conservación y Restauración de Bienes Culturales, al mes siguiente, con fecha de 28 de octubre, se aprueba y se regulan las mismas.

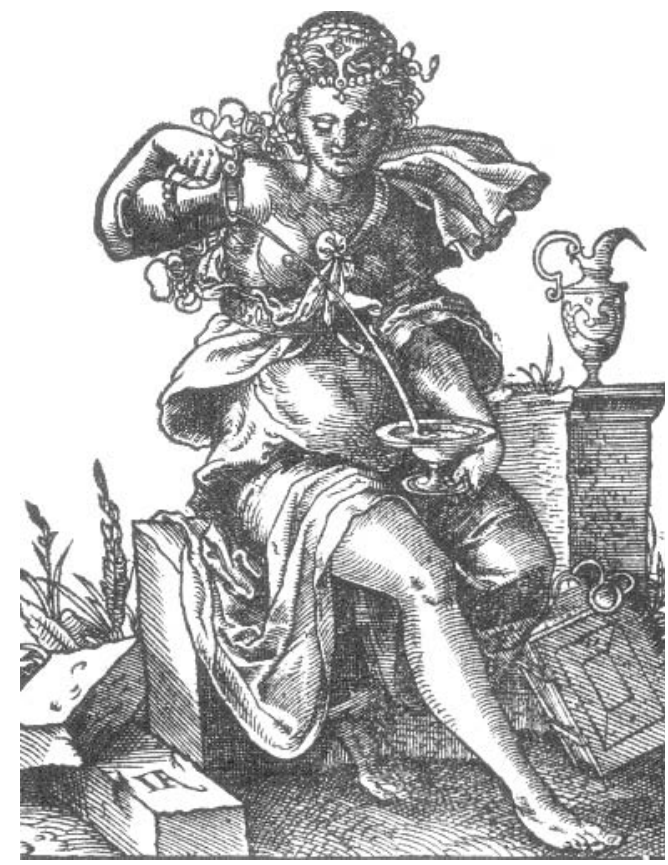


En el documento, se presenta una introducción amplia que sintetiza los principios que deben regir la formación del Conservador-Restaurador de Bienes Culturales. La importancia del texto, síntesis de los cambios y factores más importantes que han incidido en la configuración del perfil del Conservador-Restaurador de Bienes Culturales y su formación, da licencia para ser recogido en este artículo, quedando como cierre del mismo.

Apuntar finalmente que en él se establece un punto de confluencia entre el perfil y la formación defendido en el panorama europeo y el propio perfil y formación del Conservador-Restaurador español y punto de confluencia en fin, entre las enseñanzas universitarias y las enseñanzas nacidas del Instituto de Conservación y Restauración.

La presente Orden desarrolla y completa las enseñanzas mínimas para el ámbito competencial del Ministerio de Educación y Ciencia, teniendo en cuenta la complejidad y especificidad de los problemas con los que en la actualidad se han de enfrentar los Conservadores y Restauradores.

De este modo se hace preciso definir, tanto la naturaleza como las exigencias y los objetivos de la Conservación y Restauración de los Bienes Culturales, para lo cual se han tomado como referencia las normas dictadas por la UNESCO y por el Comité de Conservación del ICOM para la formación y actuación de los especialistas. Estas recomendaciones aceptadas internacionalmente, permiten establecer con claridad el perfil de los profesionales de la Conservación y Restauración que demanda la sociedad actual y las necesidades del Patrimonio Histórico mundial, apartándose por completo de las consideraciones tradicionales fundamentadas en el carácter creativo y artesanal que inspiraba las tareas de conservación y restauración de los bienes culturales.

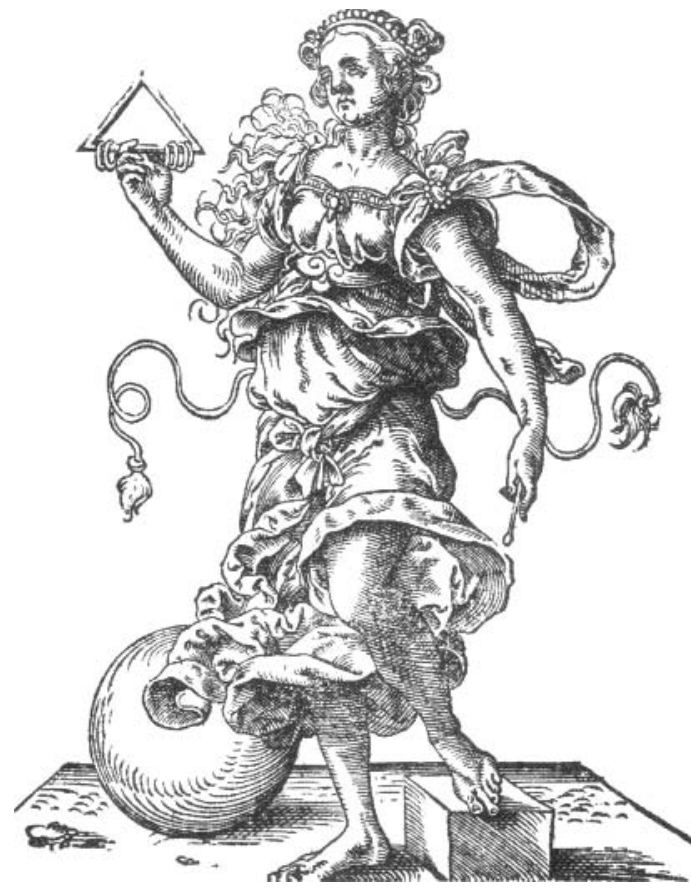

En este contexto, por una parte, la actividad del Conservador Restaurador ha de consistir, como ya se indicó en la Reunión del Comité de Conservación del ICOM de septiembre de 1984, en Copenhague, en un examen técnico, la preservación y la Conservación Restauración de los Bienes Culturales. Por ellos se determina la estructura original, los componentes del objeto, el deterioro, alteraciones y pérdidas. Así dicha actividad se ha de concretar, bien emprendiendo una acción de conservación para retardar o prevenir el deterioro, o bien restaurándolo, sacrificando en este caso, el mínimo de su integridad estética e histórica.

Por otra parte, todo proceso de actuación sobre el Patrimonio Histórico tiene como agente básico al Conservador-Restaurador de Bienes Culturales, en razón de que éste es el eje activo del diálogo interdisciplinar que se desarrolla entre documentalistas, químicos, físicos, biólogos y conservadores para establecer la diagnosis previa a cualquier actuación. Una vez establecida esta diagnosis, a de ensamblar los datos procedentes de diferentes campos, estableciendo las propuestas globales del tratamiento e instrumentando las conclusiones discutidas y aceptadas por el equipo interdisciplinar.

Esta responsabilidad de actuar directamente sobre objetos originales irremplazables, a menudo únicos y de gran valor artístico, religioso, histórico, científico, cultural, social o económico, señala la diferencia entre esta profesión y aquellas otras puramente artísticas o artesanales, siendo uno de los criterios fundamentales de esta diferencia el hecho de que por su actividad el Conservador-Restaurador no crea objetos culturales nuevos. Partiendo de estos objetivos, el presente plan de estudios responde a la necesidad de proporcionar a los futuros Conservadores-Restauradores, una formación técnica, científica y artística basada en una educación completa y general. Para ello tiene como eje fundamen-

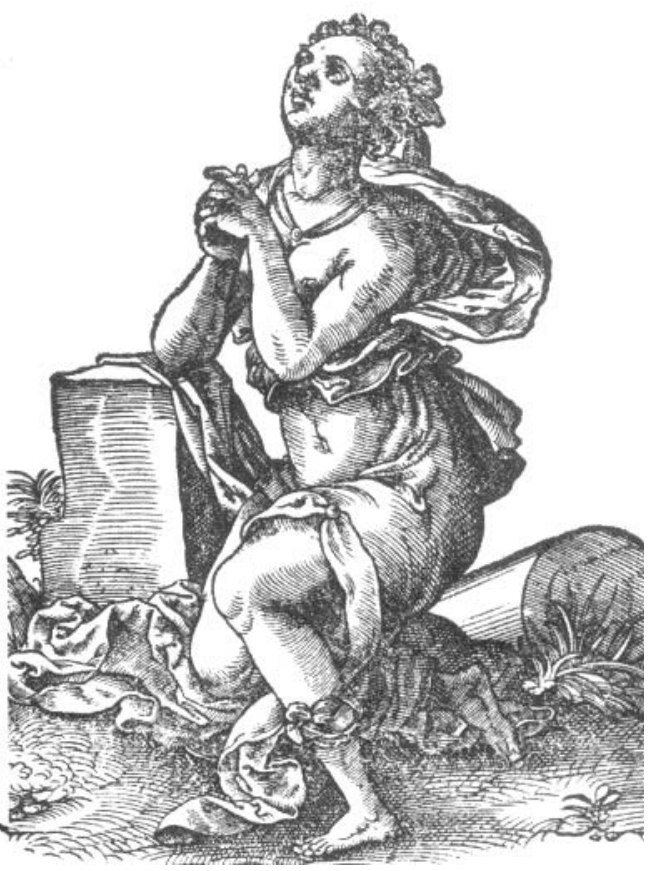


tal el carácter interdisciplinar de los conocimientos requeridos a través de las distintas áreas en que se integran sus asignaturas, comprendiendo el desarrollo de la sensibilidad y de la habilidad manual, la adquisición de un conocimiento teórico de materiales y de las técnicas y un conocimiento fundamental de la metodología científica y capaz de utilizar los avances de la más alta tecnología, con objeto de desarrollar la capacidad de resolver los problemas de la conservación por una aproximación sistemática a partir de investigaciones precisas y a través de una interpretación crítica de los resultados. Por tanto, el objetivo final de la formación es el de preparar a profesionales altamente competitivos, cualificados y capaces de realizar de forma razonada intervenciones extremadamente complejas de conservación, documentándolas a fondo a fin de que el trabajo y los datos registrados contribuyan a una mayor y profunda comprensión de los acontecimientos históricos y artísticos relativos a los objetos en curso de tratamiento. Del criterio y acertada actuación de este nuevo técnico especialista, dependerá en gran medida la preservación del Patrimonio español"32.

\section{NOTAS}

I. Decreto de 16 de noviembre (Ministerio de Educación Nacional), por el que se crea el Instituto Central de Restauración y Conservación de Obras de Arte, Arqueología y Etnología (B.O.E. 7-|2-196|). Preámbulo.

2. Real Decreto de 29 de noviembre de 1901. Reglamento para el régimen de los Museos Arqueológicos del Estado (Gaceta de Madrid, 3 de diciembre de 1901).

3. Real Decreto de 14 de mayo de 1920 del Ministerio de Instrucción Pública y Bellas Artes. Reglamento para el régimen del Museo Nacional del Prado (Gaceta de Madrid 16 de mayo de 1920).

4. Real Orden de 15 de abril de 1924, Ministerio de Instrucción Pública y Bellas Artes, Sobre el Servicio de Conservación y Restauración de Pinturas y obras de arte existentes en provincias, templos, colecciones públicas o fundaciones (Gaceta de Madrid 20 de abril de 1924).

5. Real Decreto de 24 de abril de 1924 Constitución de la Junta de Conservación y Restauración de Pinturas y Obras de Arte Antiguo.

6. "Por el momento opino que en la provincia de Sevilla, e Conservador de Museo, convenientemente dotado, teniendo dos restauradores de pinturas, y la cantidad que se proponga para la restauración de obras de arte, podría desempeñar el cargo y atender a todos los establecimientos públicos citados; haciéndose un concierto entre el Estado, la Diputación Provincial y el Municipio para el arreglo de la cuestión económica, ya que todos habían de participar de los beneficios. Para llevar a cabo este servicio con el mayor acierto, debe preceder la formación de la estadística de los mencionados establecimientos..." BOUTELOU, Claudio, "Restauraciones de Obras de Arte y de objetos históricos y arqueológicos" Carta de 16 de agosto de 1980. Boletín de la Real Academia de Bellas Artes de San Fernando, núm. 6, 1982, pág. 181

7. BERDUCOU, M., LAROQUE, C.: Le professioni del Restauro. Formazione e competenze, Instituto per I beni artistici, culturali e naturali delle Regione Emilia Romagna, Nardini Editore, Florencia, 1992. pág. 71.

8. Sobre el panorama internacional: CABRERA, J. M.: 50 años de Protección del Patrimonio Histórico Artístico 1933-1983, Ministerio de Cultura, Madrid, 1983, pág. 47. Sobre tratados internacionales suscritos por España. GARCÍA FERNÁNDEZ, J.: Legislación sobre Patrimonio Histórico,Técnos, 1987, págs. 73-104.

9. COREMANS. P.: "La Organización de un servicio nacional de preservación de Bienes Culturales", La Conservación de los Bienes Culturales. Museos y monumentos, UNESCO, 1969, pág. 77.

10. "Coremans. Paul, Doctor en ciencias por la Universidad Libre de Bruselas y ex director del Instituto Real del Patrimonio Artístico de Bruselas, Director del Centro Nacional de Investigadores Primitifs flamands (195I-1965) y profesor de la Universidad de Gante, Autor de numerosas publicaciones" en La Conservación de los Bienes Culturales Museos y Monumentos, XI, UNESCO, 1969, pág. 16.

II. Informes y trabajos del Instituto de Conservación y Restauración de Obras de Arte. Arqueología y Etnografía tomo II, Madrid, 1964 págs. 5 y 6.

12. CABRERA, J. M.: "Conservación y Restauración". 50 años de Protección del Patrimonio Histórico Artístico 1933-1983, Ministerio de Cultura, Madrid, 1983, nota 12 pág. 53, nota 12: COREMANS, P.: "Misión UNESCO en España: El Instituto Central de Conservación y Restaura ción". Texto fotocopiado, Bruselas, 1963.

13. COREMANS, P.: "Organización de un servicio naciona de preservación de los Bienes Culturales", La Conservación de los Bienes Culturales. Museos y Monumentos XI, UNESCO, 1969, págs, 77- 89, ref. bibl COREMANS, P.: La protection du patrimoine cultural dans les climats chauds et humides. Icom, 1963 y UNESCO, The Organization of museums: practical advice. París. Museums and Monuments, IX, UNESCO, 1960

14. Informes y trabajos del Instituto de Conservación y Restauración de Obras de Arte Arqueología y Etnología. Introducción de Gratiano Nieto Gallo, tomo V. 1965, pág. 6.

15. MUÑOZ COSME, A.: La conservación del Patrimonio Arquitectónico Español, Ministerio de Cultura, Madrid, 1989, págs. 44-45.

16. Instituto de Conservación y Restauración de Bienes Culturales, Prólogo de BRIGUEGA SIERRA. J. e introducción de HERNÁNDEZ GIL, D. Ministerio de Cultura, Madrid, 1990, pág. 9 y sigs.

17. Decreto 2.4/5/196| de 16 de noviembre (Ministerio de Educación Nacional) por el que se crea el Instituto Central de Restauración y Conservación y Restauración de Obras y Objetos de Arte, Arqueología y Etnología (B.O.E. 7-|2-|96|) 
18. Se recuerda: el Symposium sobre Restauración Monumental celebrado en octubre de 1959 bajo el patrocinio de la U.N.E.S.C.O, en el que estuvo presente el director del Patrimonio Real de Bélgica, Dr. Coremans, el Congreso del ICOM celebrado en Barcelona en 196I, en la que se reunieron especialistas de toda Europa, el trabajo y estudio realizado para la Restauración de la Portada de Ripoll en este mismo año, donde colaboraron el Conservador del Laboratorio Nacional de Varsovia, el restaurador del Museo de Arte de Berlín, especialistas americanos y suizos, además de especialistas españoles del Consejo Superior de Investigaciones Científicas, del Instituto de Farmacología de la Facultad de Madrid, o químicos de la Junta de la Energía Nuclear de Madrid. Son ejemplos de intercambio de conocimientos, experiencias y métodos de los primeros años del Instituto. Recogido en Informes y trabajos del Instituto de Conservación y Restauración de Obras de Arte, Arqueología y Etnología.

19. En 1967 la Biblioteca constaba de cuatro secciones fundamentales: Física y Química aplicada a la Conservación de Obras de Arte, problemas de la Conservación y Restauración, Arqueología e Historia del Arte; Y contaba con 3.070 volúmenes y 146 revistas especializadas. En 1968 "La biblioteca se ha ampliado en un fondo de 935 nuevos volúmenes". Informes y trabajos del Instituto de Conservación y Restauración de Obras de Arte, Arqueología y Etnología, Tomo VII. pág.V y Tomo VIII, pág.V, Madrid, 1967 y 1968 respectivamente.

20. Conferencia sobre Conservación de Textiles celebradas en Delf (Holanda), durante los días 6 al II de julio de 1964. The International Institute for Conservation of Historic and Artistic works. Informes y trabajos del Instituto de Conservación y Restauración de Obras de Arte, Arqueología y Etnología", IV, Madrid, 1964. Estudios en el IRPA de Bruselas sobre Textiles (1967). Estudios de Textiles en Berna (1968). Conferencia sobre la Climatología en los Museos. Celebrada en Londres, 1967, patrocinada por The Intemational Institute for Conservation of Historic and Artistic Works. Informes y trabajos del Instituto de Conservación y Restauración de Obras de Arte, Arqueología y Etnología, VII, Madrid, 1967. Para la formación del personal especializado, dos licenciados en Ciencias Químicas han sido pensionados en el Institut Royal du Patrimoine Artistique de Bruselas. Beca para el Departamento de Papel, Grabado y Dibujos a los E.E.U.U. para realizar estudios sobre Conservación y Restauración de Grabados, Dibujos, Documentos, Manuscritos y Pergaminos. Beca para especialización en Conservación de Metales en Roma bajo la dirección del Profesor H. H. Plenderleith (1968-69). Recogido en Informes y trabajos del Instituto de Conservación y Restauración de Obras de Arte, Arqueología y Etnología, Tomos VII, VIII y IX, Madrid, 1967, 1968, 1969

21. Decreto 2.415/1961, de 16 de noviembre (Ministerio de Educación Nacional), por el que se crea el Instituto Central de Restauración y Conservación de Obras de Arte, Arqueología y Etnología. (B.O.E. 7-12-1961). Preámbulo y art. $5^{\circ}$.

22. GONZÁLEZ-ÚBEDA RICO, G.: Aspectos jurídicos de la protección del Patrimonio Histórico Artístico Cultural, Madrid 1981, pág. 109.

23. Real Decreto 2.093 de 23 de julio de 1971 de Creación del Instituto de Conservación de Obras de Arte, art. décimo, (B.O.E. 20-9-197I).

24. CABRERA. J. M.: "Conservación y Restauración", 50 años de Protección del Patrimonio Histórico Artístico 1933-1983, Ministerio de Cultura, Madrid, 1983, pág. 53.
25. GONZÁLEZ-ÚBEDA RICO, G.: Aspectos jurídicos de la Protección del Patrimonio Histórico Artístico Cultural. Cultura y Comunicación 17, Ministerio de Cultura, Madrid, 1981, págs. 108-109.

26. Orden de 21 de enero de 1987 por la que se aprueba el Plan de Estudios de la Escuela de Artes Aplicadas a la Restauración. Modificación de la Escuela de Artes Aplicadas a la Restauración por Escuela de Conservación y Restauración de Bienes Culturales (B.O.E. 26-I-1987).

27. Orden de 21 de enero de 1987 por la que se aprueba el Plan de Estudios en la Escuela de Artes Aplicadas a la Restauración, (B.O.E. 26-I-1987).

28. Real Decreto 1.497/1987, de 27 de noviembre en el que se establece los planes de estudio de los títulos universitarios de carácter oficial y con validez en todo el territorio nacional.

29. Consejo de Universidades. Reformas de las Enseñanzas Universitarias. Título: Diplomado en Restauración. Propuestas alternativas, observaciones y sugerencias formuladas al informe técnico durante el periodo de información y debate públicos. Consejo de Universidades. Secretaría General, Consejo de Universidades. Ministerio de Educación y Ciencia, 1989.

30. El Instituto del Patrimonio Histórico Andaluz, lleva a cabo en 1991 un profundo estudio sobre la formación del Restaurador de Bienes Culturales, recogido en: "Informe: La problemática del Restaurador de Bienes Culturales". Este, junto al "Avance del programa de formación del Patrimonio Histórico" elaborado por el Departamento de Formación del Instituto Andaluz del Patrimonio, fueron facilitados por el director del mismo pudiéndose observar la profundidad de la investigación. El primero desarrolla y aporta los siguientes puntos y documentación: Introducción, Titulaciones, Licenciatura en Bellas Artes, especialidad de Restauración, El título del Restaurador, Contenidos posibles de las enseñanzas de los Restauradores de Bienes Muebles, Cursos de especialización y postgrado, el modelo italiano, la situación del Restaurador en la Administración, El Restaurador y la Ley de los Contratos del Estado. Presenta la siguiente documentación: Planes de Estudios de la Especialidad de Restauración de las Facultades de Bellas Artes, Plan de Estudios de la Escuela de Conservación y Restauración de Bienes Culturales, Propuesta del Consejo de Universidades:Título licenciado en Bellas Artes, Reforma de las Enseñanzas Universitarias, Perfil del Conservador Restaurador del ICOM, Documentación, normativa y Legislación de la situación italiana. Quede recogido como fuente de estudio al aportar datos y documentos de interés.

31. Real Decreto 1.387/1991, de 18 de septiembre, por el que se aprueban las enseñanzas mínimas del currículo de Conservación y Restauración de Bienes Culturales, y se regula la prueba de acceso a estos estudios (B.O.E. 30-91987), arts. 4 y 5.

32. Orden de 28 de octubre de 1991 por la que se aprueba el currículo y se regulan las enseñanzas de Conservación y Restauración de Bienes Culturales (B.O.E. I de noviembre de 1991). 